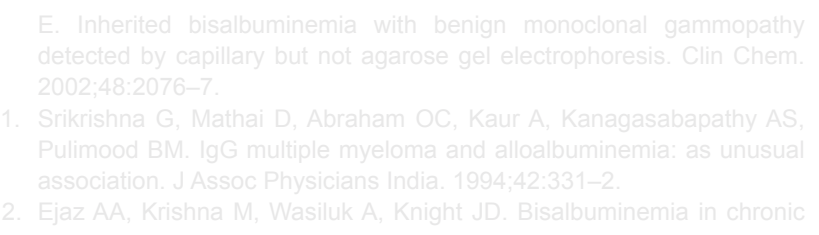

\title{
Bilateral Deep Vein Thrombosis Associated with Inferior Vena Cava Agenesis in a Young Patient Manifesting as Low Back Pain
}

\author{
Trombose Venosa Profunda Bilateral Associada a \\ Agenesia de Veia Cava Inferior em Doente Jovem \\ Manifestando-se como Dor Lombar
}

Felipe LANGER $\rrbracket^{1}$, Daiane dos SANTOS ${ }^{1}$, Gustavo SUERTEGARAY ${ }^{1}$, Carlos HAYGERT ${ }^{1}$ Acta Med Port 2017 Apr;30(4):333-337 - https://doi.org/10.20344/amp.7744

\begin{abstract}
Congenital absence of the inferior vena cava is a rare vascular anomaly, and most cases are asymptomatic. Nevertheless, patients with inferior vena cava malformations may have increased risk of deep venous thrombosis. Particularly, cases of bilateral deep venous thrombosis may arise owing to an insufficient collateral venous drainage from the lower limbs. We hereby describe a case of a previously healthy young male patient presenting with bilateral lower limb deep venous thrombosis as the initial clinical manifestation of congenital inferior vena cava agenesis. We conclude that in young patients presenting with deep venous thrombosis, especially when thrombosis occurs spontaneously, bilaterally, or recurrently, inferior vena cava anomalies should be thoroughly investigated and ruled out as appropriate.
\end{abstract}

Keywords: Low Back Pain; Vascular Malformations; Vena Cava, Inferior/abnormalities; Venous Thrombosis

\section{RESUMO}

Ausência congênita da veia cava inferior é uma anomalia vascular rara e a maioria dos casos são assintomáticos. No entanto, pacientes com malformações da veia cava inferior possuem um risco aumentado de trombose venosa profunda. Notavelmente, casos de trombose venosa profunda bilateral podem ocorrer em decorrência de drenagem venosa colateral insuficiente dos membros inferiores. Apresentamos aqui o caso de um doente que veio à nossa instituição apresentando trombose venosa profunda bilateral de membros inferiores como manifestação inicial de agenesia da veia cava inferior. Concluímos que em pacientes jovens apresentando trombose venosa profunda, especialmente quando a trombose ocorrer espontaneamente, bilateralmente, ou de forma recorrente, anomalias da veia cava inferior devem ser extensamente investigadas e descartadas.

Palavras-chave: Dor Lombar; Malformações Vasculares; Trombose Venosa; Veia Cava Inferior/anomalias congénitas

\section{INTRODUCTION}

Venous thrombosis (VT) occurs in 1 per 1000 individuals per year. ${ }^{1,2}$ The incidence of VT is unevenly distributed among age groups, as most cases affect elderly patients with identifiable risk factors for thrombogenesis. ${ }^{1,2}$ Deep venous thrombosis (DVT) in young patients, on the other hand, is an uncommon event: the rates of VT among patients under the age of 40 are ten times lower than among the elderly, and this number rises exponentially with advancing age ${ }^{3}$ Owing to an increased risk of post-thrombotic syndrome, pulmonary thromboembolism and secondary pulmonary hypertension, recurrence of thrombosis, and major anticoagulant-related bleeding, deep vein thrombosis (DVT) negatively impacts quality of life. ${ }^{1}$

Inferior vena cava (IVC) malformations are infrequent in the general population and most commonly disclosed by imaging exams performed for unrelated purposes rather than by clinical signs or symptoms. ${ }^{4}$ They mostly originate during early pregnancy between the sixth and eighth gestation weeks, a critical period wherein a complex set of vessel fusion, replacement, and disappearance takes place so as to establish the venous system as seen in the newborn. Any disturbance in this process may lead to IVC abnormalities and collateral venous return. ${ }^{5}$ Although most adult patients with IVC anomalies are asymptomatic, studies $^{3,6-9}$ have shown that this condition may significantly increase their risk of DVT and thrombosis recurrence. ${ }^{3,5}$

In this case report, we sought to describe a case of a young adult male patient that presented with bilateral lower limb DVT secondary to IVC agenesis and collateral venous return. We also discuss the epidemiology, diagnostic

1. Radiology and Imaging Diagnosis. University Hospital of Santa Maria. Rio Grande do Sul. Brazil.

$\bowtie$ Autor correspondente: Felipe Langer. felipewlanger@gmail.com

Recebido: 14 de abril de 2016 - Aceite: 19 de dezembro de 2016 | Copyright @ Ordem dos Médicos 2017 
workup, and management of thrombosis in patients with IVC anomalies, as well as the long-term prognosis of DVT associated with IVC agenesis.

\section{CASE REPORT}

A 30-year-old non-smoker male patient was referred to the emergency unit to investigate a history of recent onset, progressive acute low back pain radiating to both thighs that had started a day before and prevented him from walking or standing upright. On clinical examination, areas of ecchymosis and bilateral painful swelling were noted in both lower limbs. His pain was worsened by touch and feet dorsiflexion. He was afebrile, and his cardio-pulmonary examination was normal. His past medical history was unremarkable, and he denied use of any medications at that moment. He had not suffered any trauma or undergone recent surgery, and he was unaware of cases of DVT or thrombophilia in his family. His laboratory workup disclosed an elevated D-dimer but was otherwise normal; screening for thrombophilias was consistently negative. Given this set of clinical findings, a hypothesis of DVT was raised. Color Doppler ultrasonography of the lower limbs then revealed bilateral occlusion of femoral and popliteal veins (Fig. 1). A computed tomography (CT) scan of the abdomen and
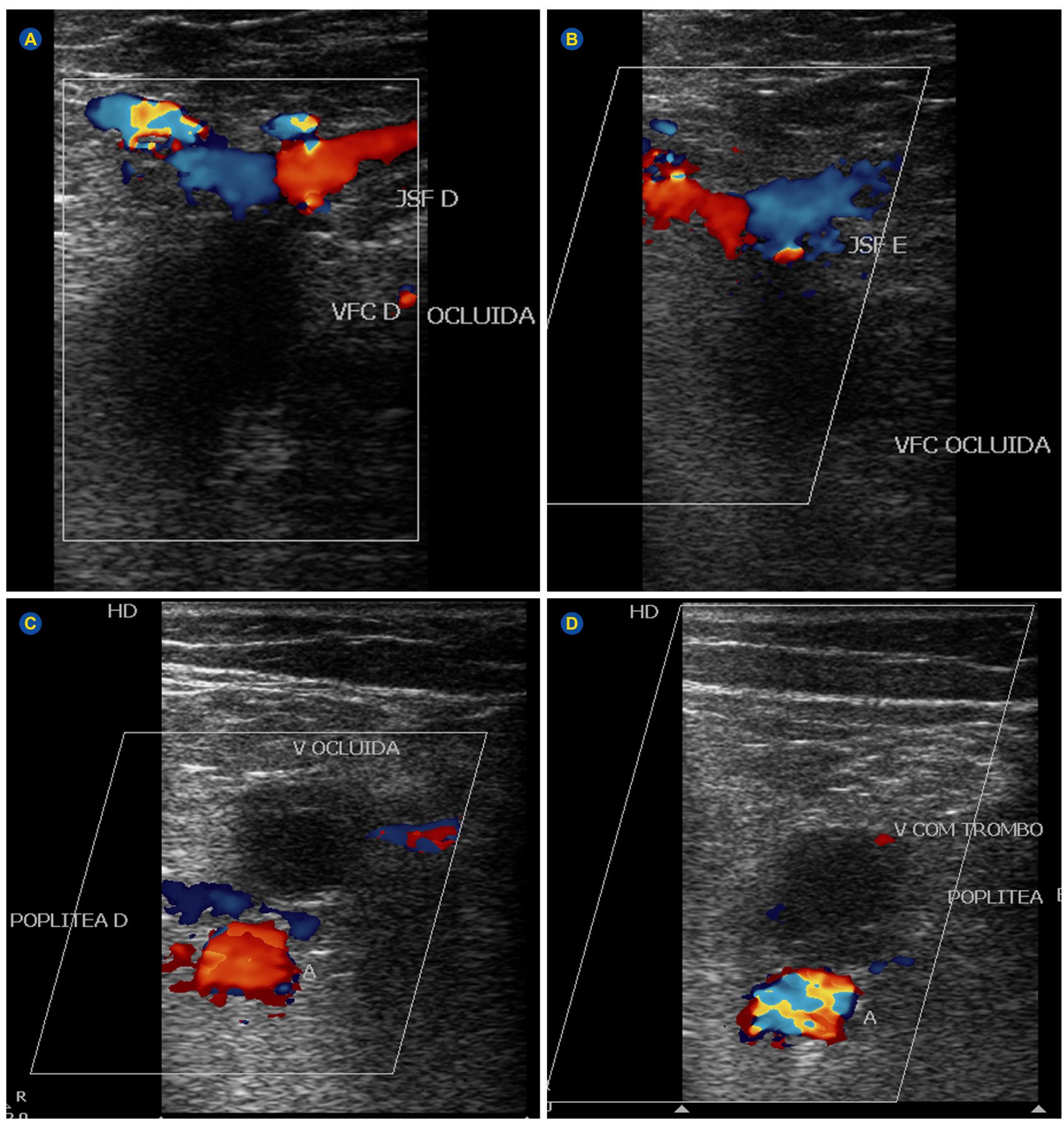

Figure 1 - Doppler ultrasound examination of the inferior limbs shows thrombotic obstruction of both right $(A)$ and left $(B)$ common femoral veins and right $(C)$ and left $(D)$ popliteal veins 


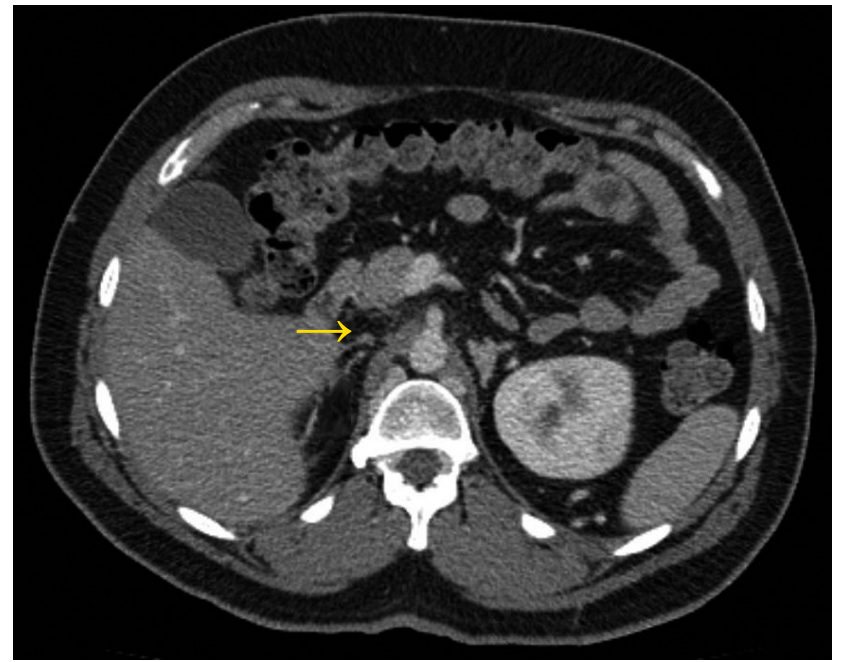

Figure 2 - Axial abdominal computed tomography shows absence of the suprarenal segment of inferior vena cava (arrow)

pelvis was then performed and disclosed absence of the suprarenal portion of the IVC (Fig. 2), with extensive venous collateralization through the azygous and lumbar veins (Fig. 3). The patient was treated in a conservative fashion with anticoagulant therapy consisting of subcutaneous heparin followed by warfarin, as well as compression stockings. He showed significant symptom improvement and was discharged asymptomatic. As the patient had no additional risk factors for thrombosis aside from his IVC anomaly, oral anticoagulant therapy was discontinued after a year without recurrences.

\section{DISCUSSION}

Congenital venous malformations occur in approximately $1 \%$ of the population, and approximately half of cases consist of IVC abnormalities. ${ }^{3}$ Anomalies of IVC development are most often asymptomatic and probably underdiagnosed because the IVC cannot be properly assessed by abdominal B-mode nor Doppler ultrasonography. However, in young patients presenting with spontaneous lower extremity DVT, the prevalence of underlying IVC malformations reaches up to $5 \%$ 6,8; consequently, IVC anomaly is considered an important risk factor for thromboembolism even when no additional risk factors for thrombosis can be identified. ${ }^{8}$ Therefore, all young patients presenting with spontaneous lower limb DVT should undergo cross-sectional imaging investigation to rule out IVC anomalies.
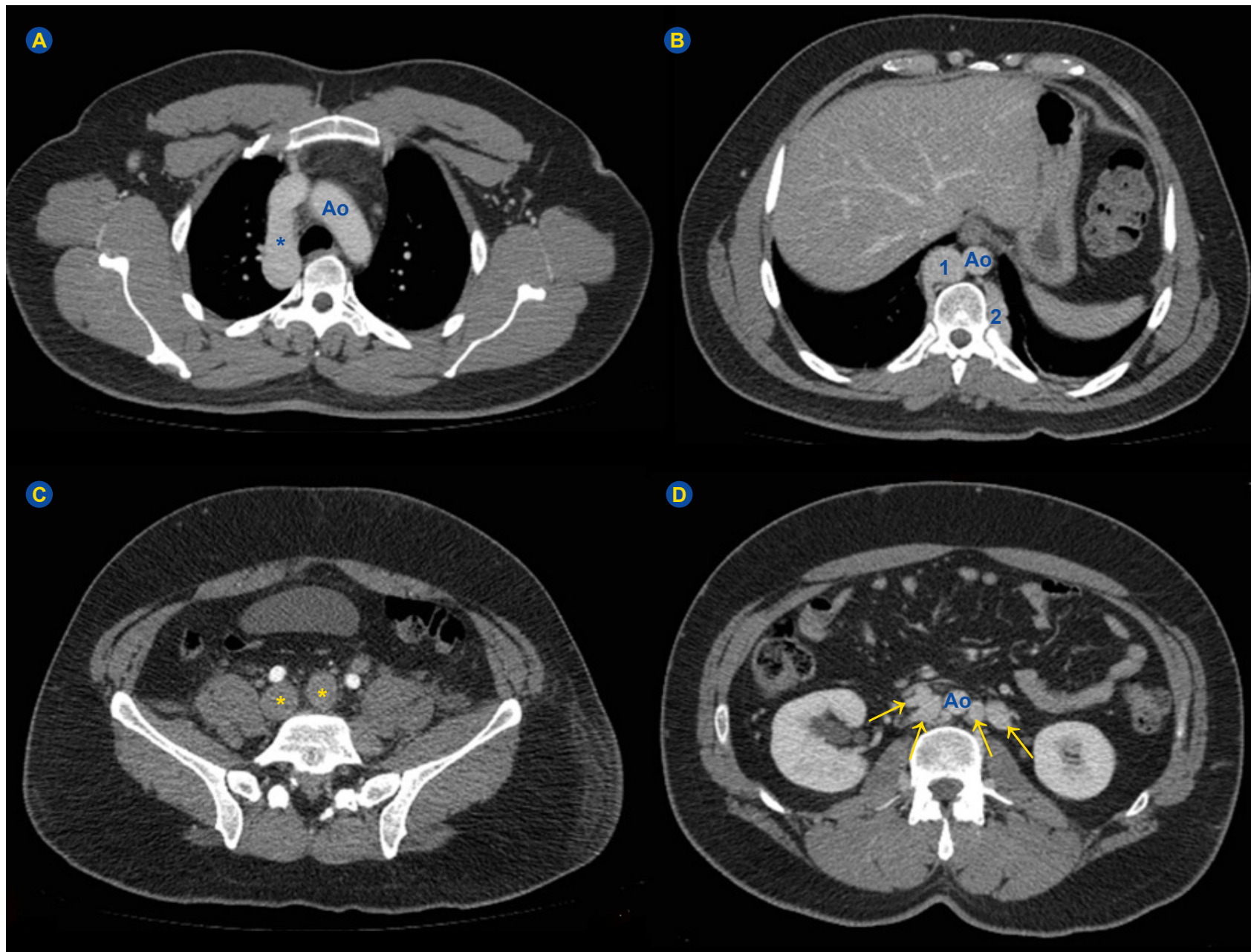

Figure 3 - Axial computed tomography (CT) of the collateral venous return. A: Axial chest CT shows an enlarged azygous vein (asterisk), whose size is comparable to the aortic arch (Ao). B: A dilated azygous vein (1) and a paravertebral collateral vein (2) are visible. C: Both common iliac veins are enlarged owing to thrombotic obstruction (asterisks). D: Multiple paravertebral collateral veins are present (arrows). 
Partial or complete agenesis of IVC predisposes to thromboembolic events presumably due to relative venous stasis secondary to collateral venous return. In most patients with IVC agenesis, an extensive collateral venous system develops to compensate for inadequate blood return to the right heart, most frequently through retroperitoneal and abdominal wall vessels. ${ }^{6}$ However, this alternative circulation pathway often proves insufficient to drain the blood from inferior limbs, particularly in period of increased demands, such as vigorous physical exertion, or when additional risk factors for thrombosis are concomitantly present, such as immobilization, trauma, recent surgery, or use of oral contraceptives. Notably, patients demonstrating absent/partial IVC who develop DVT are usually younger, have higher thrombosis location, and are more likely to have bilateral and recurrent thrombosis than the average DVT patients. In addition, DVT secondary to IVC anomaly disproportionally affects male patients, but the reason for this is still unclear. ${ }^{3,6}$

Some features of the case hereby described are worth mentioning. In the largest case series of lower extremity DVT related to IVC agenesis, most patients had thrombosis after a precipitating factor, mostly unusual and intense physical exertion. ${ }^{10}$ Our patient, on the other hand, denied any intense physical activity or other potential triggers for thrombosis before the onset of symptoms. Although venous thrombosis is a multifactorial disease and often requires various risk factors to manifest in young patients, ${ }^{1,2}$ our findings support IVC agenesis as an independent and sufficient risk factor for the development of thromboembolism. Therefore, this condition should be suspected in any young patient presenting with lower limb DVT even in the absence of additional risk factors. ${ }^{3,8,11-13}$ Another interesting feature is the pattern of pain reported by our patient. Most cases of bilateral DVT manifested acutely either as lower extremity pain, edema, and erythema or as localized low back pain, which was unilateral in many patients despite bilateral thrombosis. ${ }^{8,10}$ A pattern of bilateral low back pain radiating to buttocks and thighs, however, is far more unusual. $^{8}$ In the absence of other symptoms or signs ascribable to thrombosis, this symptom could point to a neurogenic cause of back pain, such as radicular compression, and potentially lead to misdiagnosis. In this setting, cross-sectional imaging studies play an important role in differentiating between causes of low back pain, and physicians should be aware of this uncommon but possible manifestation of proximal, bilateral thrombosis.

Since B-mode and Doppler abdominal ultrasonography cannot assess the IVC anatomy properly, CT and MRI play an important role in diagnosing IVC anomalies. To avoid underdiagnoses, all young patients with unprovoked DVT, especially those with bilateral disease, should be screened for IVC abnormalities through CT or MRI when CT is contraindicated. ${ }^{7}$ Other clues for the diagnosis of IVC anomalies include enlargement of the azygous vein on chest radiography (due to collateral venous return), presence of abdominal collateral circulation on clinical examination, severe venous insufficiency at a young age, and male gender. ${ }^{14,15}$ Although less commonly, complete or partial agenesis of the IVC may also present concomitantly with other organ abnormalities, such as congenital heart defects (dextrocardia, septal defects, pulmonary artery stenosis, single atrium, and transposition of great vessels), polysplenia, asplenia, inversion of bowel viscera, and kidney hypoplasia. ${ }^{15,16}$

The impact of IVC agenesis in the long-term prognosis of DVT is still unclear. ${ }^{8}$ Patients are generally advised to maintain anticoagulation for at least three months following DVT to avoid early recurrence. Nevertheless, maintenance of lifelong anticoagulation is controversial and has been recently challenged by the finding that patients with IVC anomalies do not seem to have a higher risk of DVT recurrence after withdrawal of anticoagulant ${ }^{14}$; even so, many authors still support long-term anticoagulation, particularly if additional risk factors for thrombosis are present. ${ }^{12}$ Nonpharmacologic and universally recommended preventive measures include use of compression stockings and lifestyle adjustment for reducing the bleeding risk while under anticoagulation therapy. Surgical intervention employing thrombectomy and bypass grafts are warranted only for those patients with rapid deterioration of chronic venous insufficiency and for those presenting with DVT and concomitant collapse of the collateral venous drainage. ${ }^{17}$

Differential diagnoses for IVC agenesis/hypoplasia include hypercoagulable states, chronic venous insufficiency, and IVC thrombosis secondary to renal cell carcinoma or other predisposing conditions. In addition, azygous vein dilation is often appreciable and may simulate paravertebral or mediastinal masses on chest radiographs. Besides that, superficial collateral abdominal veins may simulate portal hypertension. Unilateral flank pain may be mistaken for renal diseases by the attending physician, whereas bilateral low back pain without accompanying signs of thrombosis can pose a diagnostic challenge, as discussed previously..$^{12}$ The best approach to avoid diagnostic pitfalls consists of having a high index of suspicion, confirming the diagnosis of DVT with US, and identifying the IVC anomaly through CT or MRI scans as appropriate.

In conclusion, IVC agenesis should be suspected in any young patient presenting with spontaneous lower limb DVT, especially if male and presenting bilateral disease. Other less common manifestations include low back pain as reported by our patient and superficial collateral abdominal veins on examination. Absence of additional risk factors for thrombosis or apparent precipitating factors should not preclude an extensive investigation for vascular anomalies in these patients, since IVC agenesis may independently predispose to lower limb thrombosis. Finally, anticoagulation coupled with lifestyle changes and compression stockings is usually the therapy of choice for these patients, but data about the optimal timing of anticoagulation are still lacking.

\section{DATA CONFIDENTIALITY}

The authors declare having followed the protocols in use 
at their working center regarding patient's data publication.

\section{CONFLICTS OF INTEREST}

The authors have no conflicts of interest to disclose.

\section{REFERENCES}

1. Cushman M. Epidemiology and risk factors for venous thrombosis. Semin Hematol. 2007;44:62-9.

2. Rosendaal FR. Thrombosis in the young: epidemiology and risk factors. A focus on venous thrombosis. Thromb Haemost. 1997;78:1-6.

3. Chee Y-L, Culligan DJ, Watson HG. Inferior vena cava malformation as a risk factor for deep venous thrombosis in the young. $\mathrm{Br} \mathrm{J}$ Haematol. 2001;114:878-80.

4. Bass JE, Redwine MD, Kramer LA, Huynh PT, Harris JH. Spectrum of congenital anomalies of the inferior vena cava: cross-sectional imaging findings. Radiographics. 2000;20:639-52.

5. Obernosterer A, Aschauer M, Schnedl W, Lipp RW. Anomalies of the inferior vena cava in patients with iliac venous thrombosis. Ann Intern Med. 2002;136:37-41.

6. Pop S, Opincaru I. Anomalies of the inferior vena cava in patients with deep venous thrombosis. Pictorial essay. Med Ultrason. 2012;14:53-9.

7. Martinou C, Krishnasamy S, Varadhan L, Jose B. Absent inferior vena cava: an unusual cause of recurrent deep vein thrombosis. $\mathrm{Br} \mathrm{J}$ Hosp Med. 2015;76:247.

8. Halparin J, Monagle P, Newall F. Congenital abnormalities of the inferior vena cava presenting clinically in adolescent males. Thromb Res. 2015;135:648-51.

9. Sagban TA, Scharf RE, Wagenhäuser MU, Oberhuber A, Schelzig $\mathrm{H}$, Grabitz K, et al. Elevated risk of thrombophilia in agenesis of the vena cava as a factor for deep vein thrombosis. Orphanet J Rare Dis. 2015;10:3

10. Lambert M, Marboeuf $\mathrm{P}$, Midulla M, Trillot N, Beregi JP, Mounier-Vehier

\section{FUNDING SOURCES}

No grants or any other type of support was received for this work.

C, et al. Inferior vena cava agenesis and deep vein thrombosis: 10 patients and review of the literature. Vasc Med. 2010;15:451-9.

11. Gayer G, Luboshitz J, Hertz M, Zissin R, Thaler M, Lubetsky A, et al. Congenital anomalies of the inferior vena cava revealed on CT in patients with deep vein thrombosis. Am J Roentgenol. 2003;180:72932.

12. Ismail EA, Azab AF, Jayappa S, Al-Qattan H. Congenital absence of the infrahepatic segment of the inferior vena cava with deep venous thrombosis in an 8.5-year-old boy. Pediatr Int. 2010;52:e117-20.

13. Kalicki B, Sadecka M, Wawrzyniak A, Kozinski P, Dziekiewicz M, Jung A. Absence of inferior vena cava in 14-year old boy associated with deep venous thrombosis and positive mycoplasma pneumoniae serum antibodies- a case report. BMC Pediatr. 2015;15:40.

14. Riera-Mestre A, Romera A, Fernández A, Corbella X. Long-term followup after anticoagulant treatment withdrawal in patients with deep venous thrombosis and inferior vena cava agenesis. Eur J Intern Med. 2014;25:e113-4.

15. Tofigh AM, Coscas R, Koskas F, Kieffer E. Surgical management of deep venous insufficiency caused by congenital absence of the infrarenal inferior vena cava. Vasc Endovascular Surg. 2008;42:58-61.

16. Tsuji $Y$, Inoue $T$, Murakami H, Hino $Y$, Matsuda $H$, Okita $Y$. Deep vein thrombosis caused by congenial interruption of the inferior vena cava. $A$ case report. Angiology. 2001;52:721-5.

17. Sagban TA, Grotemeyer D, Balzer KM, Tekath B, Pillny M, Grabitz K, et al. Surgical treatment for agenesis of the vena cava: a single-centre experience in 15 cases. Eur J Vasc Endovasc Surg. 2010;40:241-5. 